\title{
LETTER TO THE EDITOR \\ The role of censuses, surveys and demographic surveillance systems in measuring health gaps between the rich and the poor in rural Africa
}

\author{
A Sibanda ${ }^{1}$, HV Doctor ${ }^{2}$, The late A Noumbissi ${ }^{3}$ \\ ${ }^{1}$ Department of Economic and Social Affairs, United Nations, New York, USA \\ ${ }^{2}$ Mailman School of Public Health, Department of Population and Family Health, Columbia \\ University, New York, USA \\ ${ }^{3}$ African Census Analysis Project, Population Studies Centre, University of Pennsylvania, \\ Philadelphia, USA
}

Submitted: 20 July 2011; Published: 15 February 2012

Sibanda A, Doctor HV, Noumbissi A

The role of censuses, surveys and demographic surveillance systems in measuring health gaps between the rich and the poor in rural Africa

Rural and Remote Health 12: 1868. (Online) 2012

Available: http://www.rrh.org.au

\section{Dear Editor}

Compared with Europe and North America, few African countries have consistently undertaken health and standard of living surveys that collect information ranging from socioeconomic status (SES) to self-reported morbidity. Because of the lack of these data, a detailed picture of the nature and magnitude of inequalities in health is lacking. Data from Demographic and Health Surveys (DHS) and censuses have shown considerable inequalities in mortality across socioeconomic groups as well as across ethnic and regional lines ${ }^{1-3}$. However, to get a clearer picture of inequalities in health would require the combined use of cross-sectional and surveillance data on fatal and non-fatal health outcomes. This combination of data sources would also give researchers the leverage to examine the sources of inequality as well as explanations behind the observed inequalities ${ }^{4}$.

In the past few decades, Africa has progressed dramatically from being a 'data-poor' to a 'data-rich' continent, with most countries conducting at least two censuses and several DHSs. However, most census information has been greatly underutilized and in some cases it has deteriorated due to poor storage. In order to avoid this unfortunate loss of data, the African Census Analysis Project (ACAP, based at the University of Pennsylvania), in collaboration with various African census bureaus and universities has managed to 
recover and preserve census micro-data from 1970, 1980, and 1990 rounds of census enumeration. At the last count, the ACAP collection consisted of micro-data from 55 censuses for 26 African countries. Another project, the IPUMS International based at the University of Minnesota Population Centre, also has a database of census data for selected African countries. These data are essential to our understanding of the demography of Africa, including the health gaps between rich and poor.

Although census data are limited in depth and separated by large data collection intervals, often 10 years or more, their major advantage is that they cover the whole country. In the context of measuring gaps in health between the rich and the poor, the potential provided by these data is immense. By virtue of their size, census micro-data yield more statistically robust estimates of trends in inequality in child mortality, unlike assessments derived from DHSs ${ }^{2}$. And to overcome the lack of individual-level data on income and other measures of SES, census data can be used to create an index of household wealth and other community-level measures of SES that can then be used to assess inequalities in mortality and morbidity. More importantly, censuses provide a wealth of information on housing conditions, access to water, type of toilet facilities, and occupation types and other individuallevel attributes. For researchers interested in examining imbalances in the distribution of human resources for health, which often lead to inequities in the delivery of health services and health outcomes, censuses can be an important source of occupation-type statistics, including health workforce statistics. This information can be used to map the geographic distribution of the health workforce and to calculate indicators that reflect the capacity of healthcare systems, such as the health worker-to-population ratio ${ }^{5}$. Census data can also provide the limited materialistic and individual-level sources of inequality identified by Feinstein's conceptual decomposition of factors, explaining health inequalities ${ }^{4}$ (Fig1).

The proliferation of surveys such as the DHS and the World Bank's Living Standards Surveys as well as Health and Demographic Surveillance Systems (HDSS) in largely rural
African settings complements these census data. For instance, while HDSS data provide detailed person-years of observation, with data on births, deaths, migrations, morbidity and SES variables on small local populations within a country, and are usually collected continuously ${ }^{6}$, census data provide a national context for such field-site data. More importantly, because they collect data on a continuous basis, HDSS are more likely to capture sources of inequality associated with all four of Feinstein's boxes (Fig1), offering valuable opportunities to explore the sources of and explanations for health inequalities.

Opportunities to maximize the use of these data now exist due to easy access to DHS data and the collaboration among the International Network of field sites with continuous Demographic Evaluation of Populations and Their Health in developing countries (INDEPTH), African Central Statistical Offices and ACAP. The HDSS sites, which largely collect data from rural and disadvantaged populations, can work together through the INDEPTH Network to collect comparable data on health inequalities. The use of a standard core questionnaire has helped achieve this goal. The HDSS data also allows researchers to examine the causes of health inequality across countries.

Because the longitudinal nature of HDSS data allows researchers to capture the temporary and spatial dimensions of health inequalities, they have the added potential of broadening the scientific framework of health inequalities research $^{6}$. In other words, HDSS data provide the leverage to examine inequalities in health from a life-course perspective as well as from society-level and spatial dimension perspectives; researchers can actually collect individual-level information on health and wellbeing before health problems begin. These health problems can then be followed up and analyzed within the context of individual, household, and community-level contextual variables, thereby enhancing our understanding of the pathways linking SES to health inequalities. This life-course strategy is important in identifying the stages of rolling out different interventions ${ }^{7}$. Such an in-depth analysis cannot be carried out using DHS type surveys or census micro-data. 


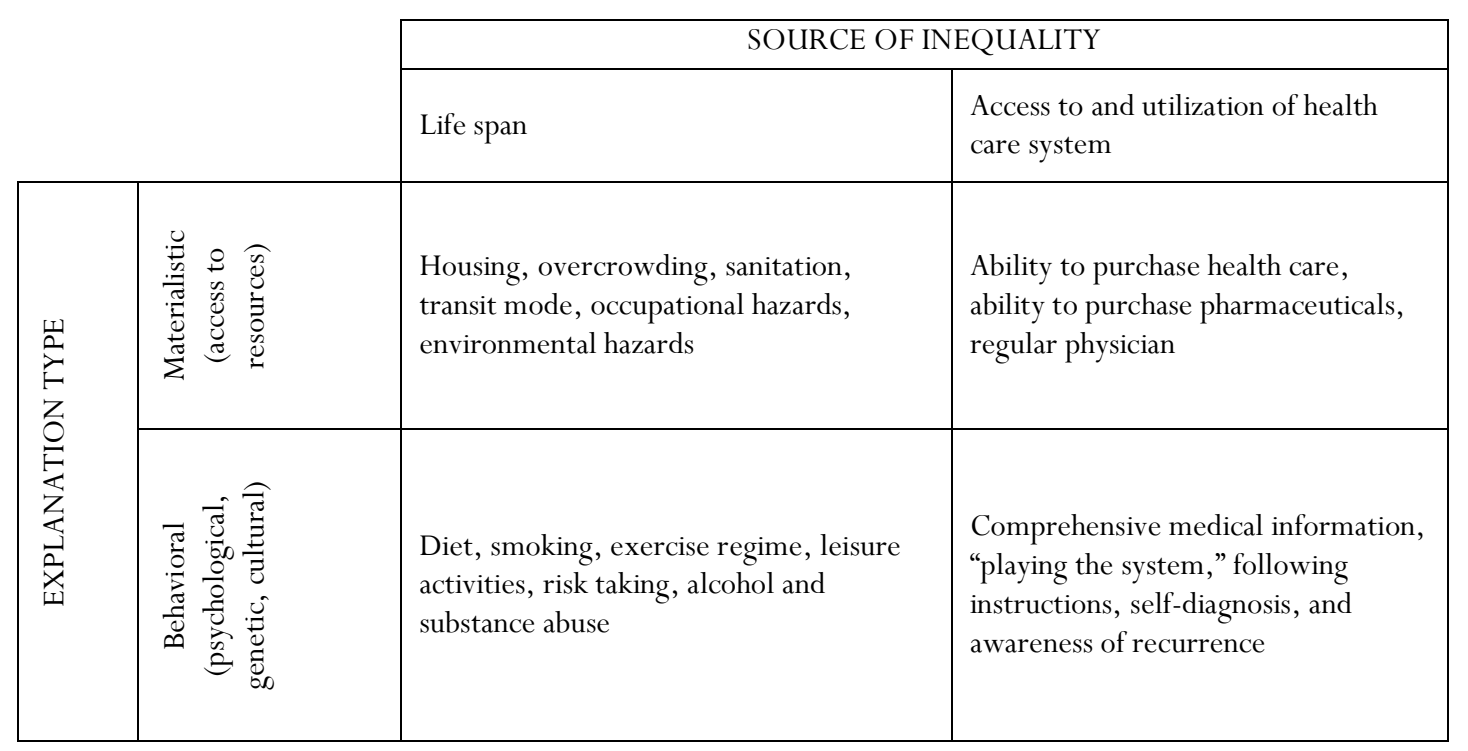

Figure 1: Conceptual decomposition of factors explaining health inequalities. Reproduced from ${ }^{4}$, with permission of the publisher.

For researchers interested in accessing HDSS data, collaboration with scientists from HDSS sites is recommended. However, the INDEPTH Network (www.indepth-network.org) supports wider and responsible access to data generated by its member centers in Africa, Asia and Oceania. To achieve this, the Network has established iSHARE (www.indepth-ishare.org) to make data widely and freely available to all researchers and decision-makers. Contact information for HDSS member sites is also available on the INDEPTH Network website; and DHS data can be accessed at http://www.measuredhs.com/.

A Sibanda ${ }^{1}, \mathrm{PhD}, \mathrm{H}$ Doctor $^{2}, \mathrm{PhD}$ and the late $\mathrm{A}$ Noumbissi ${ }^{3}$, PhD

${ }^{1}$ Department of Economic and Social Affairs, United Nations,

${ }^{2}$ Department of Population and Family Health, Mailman School of Public Health, Columbia University, New York, and ${ }^{3}$ African Census Analysis Project, Population Studies
Centre, University of Pennsylvania, Philadelphia, USA

\section{References}

1. Timaeus IM. Adult mortality. In: KA Foote, KA Hill, LG Martin (Eds). Demographic change in Sub-Saharan Africa. Washington, DC: National Academy, 1993; 218-255.

2. Ewbank CD, Gribble JW (Eds). Effects of health programs on child mortality in Sub-Saharan Africa. In: Panel on Population Dynamics of sub-Saharan Africa, Committee on Population. Washington, DC: National Academy Press, 1993.

3. Farah AA, Preston SH. Child mortality differentials in Sudan. Population and Development Review 1982; 8: 365-382.

4. Feinstein JS. The relationship between socioeconomic status and health: a review of the literature. The Milbank Quarterly 1993; 71(2): 279-322.

5. Gupta N, Zurn P, Diallo K, Dal Poz MR. Uses of population census data for monitoring geographical imbalance in the health workforce: snapshots from three developing countries. International Journal for Equity in Health 2003; 2(11): 1-12. 
The International Electronic Journal of Rural and Remote Health Research, Education Practice and Policy

6. Ngom P, Binka FN, Phillips JF, Pence B, Macleod B. Demographic surveillance and health equity in sub-Saharan Africa. Health Policy and Planning 2001; 16(4): 337-344.
7. Mackenbach JP, Kunst AE. Measuring the magnitude of socioeconomic inequalities in health: an overview of available measures illustrated with two examples from Europe. Social Science and Medicine 1997; 44: 757-771. 